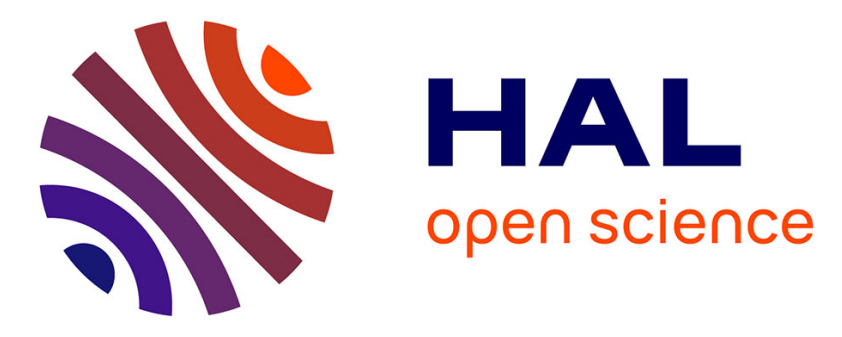

\title{
Extreme dielectric strength in boron doped homoepitaxial diamond
}

Pierre-Nicolas Volpe, Pierre Muret, Julien Pernot, Franck Omnès, Tokuyuki Teraji, Yasuo Koide, François Jomard, Dominique Planson, Pierre Brosselard, Nicolas Dheilly, et al.

\section{To cite this version:}

Pierre-Nicolas Volpe, Pierre Muret, Julien Pernot, Franck Omnès, Tokuyuki Teraji, et al.. Extreme dielectric strength in boron doped homoepitaxial diamond. Applied Physics Letters, 2010, 97 (22), pp.223501. 10.1063/1.3520140 . hal-00734714

\section{HAL Id: hal-00734714 https://hal.science/hal-00734714}

Submitted on 24 Sep 2012

HAL is a multi-disciplinary open access archive for the deposit and dissemination of scientific research documents, whether they are published or not. The documents may come from teaching and research institutions in France or abroad, or from public or private research centers.
L'archive ouverte pluridisciplinaire HAL, est destinée au dépôt et à la diffusion de documents scientifiques de niveau recherche, publiés ou non, émanant des établissements d'enseignement et de recherche français ou étrangers, des laboratoires publics ou privés. 


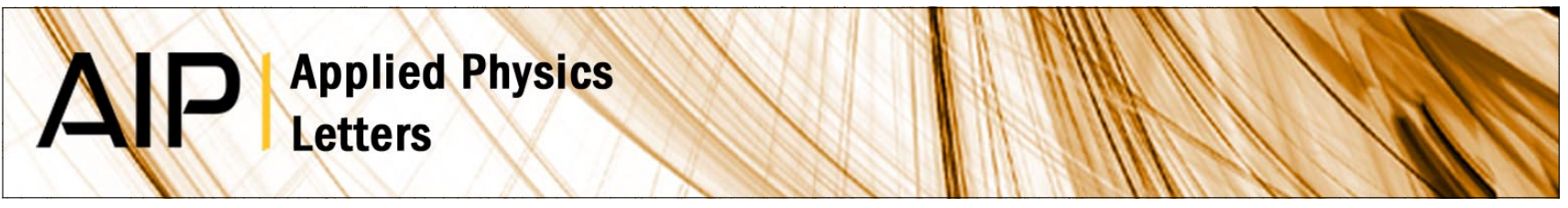

\section{Extreme dielectric strength in boron doped homoepitaxial diamond}

Pierre-Nicolas Volpe, Pierre Muret, Julien Pernot, Franck Omnès, Tokuyuki Teraji et al.

Citation: Appl. Phys. Lett. 97, 223501 (2010); doi: 10.1063/1.3520140

View online: http://dx.doi.org/10.1063/1.3520140

View Table of Contents: http://apl.aip.org/resource/1/APPLAB/v97/i22

Published by the American Institute of Physics.

\section{Related Articles}

Systematic studies of the nucleation and growth of ultrananocrystalline diamond films on silicon substrates coated with a tungsten layer

J. Appl. Phys. 111, 124328 (2012)

Resistive switching behavior in diamond-like carbon films grown by pulsed laser deposition for resistance switching random access memory application

J. Appl. Phys. 111, 084501 (2012)

Multiphonon effects on the optical emission spectra of the nitrogen-vacancy center in diamond at different temperatures

J. Appl. Phys. 111, 063519 (2012)

Surface transfer doping of hydrogen-terminated diamond by C60F48: Energy level scheme and doping efficiency J. Chem. Phys. 136, 124701 (2012)

The mechanical properties of various chemical vapor deposition diamond structures compared to the ideal single crystal

App. Phys. Rev. 2012, 3 (2012)

\section{Additional information on Appl. Phys. Lett.}

Journal Homepage: http://apl.aip.org/

Journal Information: http://apl.aip.org/about/about_the_journal

Top downloads: http://apl.aip.org/features/most_downloaded

Information for Authors: http://apl.aip.org/authors

\section{ADVERTISEMENT}

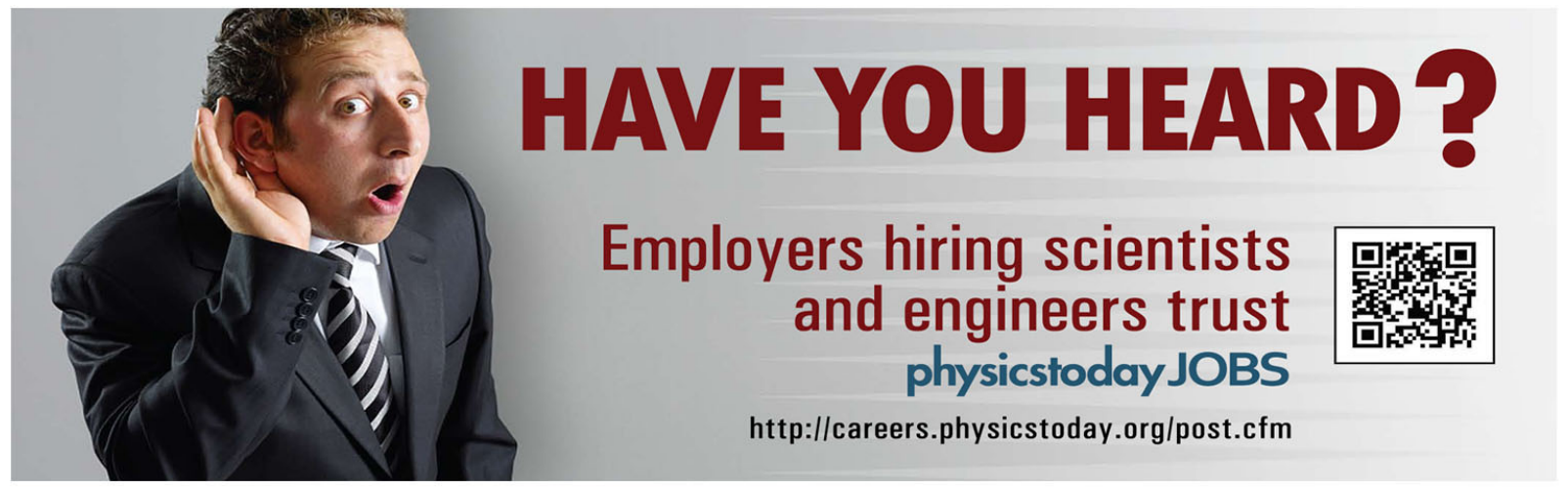




\title{
Extreme dielectric strength in boron doped homoepitaxial diamond
}

\author{
Pierre-Nicolas Volpe, ${ }^{1, a)}$ Pierre Muret, ${ }^{1}$ Julien Pernot, ${ }^{1}$ Franck Omnès, ${ }^{1}$ Tokuyuki Teraji, ${ }^{2}$ \\ Yasuo Koide, ${ }^{2}$ François Jomard, ${ }^{3}$ Dominique Planson, ${ }^{4}$ Pierre Brosselard, ${ }^{4}$ \\ Nicolas Dheilly, ${ }^{4}$ Bertrand Vergne ${ }^{5}$ and Sigo Scharnholz ${ }^{5}$ \\ ${ }^{1}$ Institut Néel, CNRS and Université Joseph Fourier, 25 rue des Martyrs, BP 166, 38042 Grenoble \\ Cedex 9, France \\ ${ }^{2}$ National Institute for Materials Science, 1-1 Namiki, Tsukuba, Ibaraki 305-0044, Japan \\ ${ }^{3}$ GEMaC-Campus CNRS de Meudon, 1 place Aristide Briand, 92195 Meudon, France \\ ${ }^{4}$ AMPERE-UCBL-INSA, 20 avenue Albert Einstein, 69621 Villeurbanne Cedex, France \\ ${ }^{5}$ ISL, French-German Research Institute of Saint Louis, 5 rue Général Cassagnou, 68301 Saint-Louis, France
}

(Received 29 July 2010; accepted 4 November 2010; published online 29 November 2010)

\begin{abstract}
The fabrication of Schottky diodes withstanding breakdown voltages up to $10 \mathrm{kV}$ is demonstrated. A corresponding electric field of $7.7 \mathrm{MV} / \mathrm{cm}$ at the center of the diode is evaluated with the help of a two-dimensional finite elements software. These properties result from a net shallow acceptor concentration below $10^{16} \mathrm{~cm}^{-3}$ in the first micrometers of an epitaxial film with optimized crystalline quality and a special oxidizing treatment of its surface, allowing the true dielectric strength of bulk diamond to be revealed. (C) 2010 American Institute of Physics.
\end{abstract}

[doi:10.1063/1.3520140]

Homoepitaxial diamond has been recognized by Landstrass $\mathrm{et} \mathrm{al.}{ }^{1}$ as the semiconductor having the highest breakdown electric field of at least $20 \mathrm{MV} / \mathrm{cm}$, much larger than in other wide band gap semiconductors. Moreover, its other properties generally exceed those of other semiconductors, such as thermal conductivity, ${ }^{2}$ carriers velocity, ${ }^{3}$ and mobility. ${ }^{3-6}$ These reasons make diamond a natural choice for high voltage and high power electronic devices. Indeed, a Schottky diode with a $6.7 \mathrm{kV}$ breakdown voltage has already been demonstrated. ${ }^{7}$ Another result pertaining to devices withstanding 8 and $12 \mathrm{kV}$ has been published, ${ }^{8}$ but with neither evidence of any rectifying behavior nor electric field estimation and with a current density increased by more than one decade as compared to Ref. 7. Various authors who have also implemented diodes made of a metal deposited on single crystalline diamond layers with boron doping concentration in the range of $10^{15}-10^{17} \mathrm{~cm}^{-3}$ showed lower limits of the maximum reverse voltage and avalanche breakdown fields not exceeding $4 \mathrm{MV} / \mathrm{cm}^{9-12}$ Higher fields were evidenced only in the case of boron concentrations near $10^{18} \mathrm{~cm}^{-3}, 1,13,14$ which are inappropriate for high voltage operation. Such low breakdown fields may be due to surface (or subsurface $)^{15}$ and interface defects rather than to the bulk properties of the diamond epilayer, since Teraji et al. ${ }^{16}$ have recently shown that a surface treatment based on ozone produced by a deep ultraviolet xenon lamp in vacuum (vuv, wavelength of $172 \mathrm{~nm}$ ), decreases the reverse current density under $1 \mathrm{kV}$ bias voltage at much smaller values than achieved by any other treatment. To check this hypothesis, new diamond diodes have been fabricated and measured at higher reverse voltages. We show here that such a treatment applied to a diamond epilayer permits to reach breakdown voltages up to $10 \mathrm{kV}$ and corresponding avalanche breakdown fields in the range of $7-9.3 \mathrm{MV} / \mathrm{cm}$ beneath the Schottky contact. In the following, growth conditions,

\footnotetext{
${ }^{a}$ Author to whom correspondence should be addressed. Electronic mail: pierre-nicolas.volpe @ cea.fr. Present address: CEA LIST, Diamond Sensors Laboratory, 91191 Gif-sur-Yvette, France.
}

cathodoluminescence characterization, and surface treatment are briefly described. Then, the issue of depassivation of boron acceptors is addressed simultaneously with secondary ion mass spectrometry (SIMS), current-voltage, and capacitance-voltage $(\mathrm{C}-\mathrm{V})$ measurements, the last ones allowing to derive the net doping concentration profile. Finally, high voltage measurements and electric field evaluation are presented and discussed.

Homoepitaxial diamond layers have been prepared on $3 \times 3 \mathrm{~mm}^{2}$, (100) oriented Ib substrate, by microwave plasma enhanced chemical vapor deposition in a silica reactor with $4 \%$ of $\mathrm{CH}_{4}$ in hydrogen under a pressure of 30 torr and a temperature of $830^{\circ} \mathrm{C}$, without intentional introduction of boron. The roughness of the substrate was measured by atomic force microscopy to be $2-5 \mathrm{~nm}$ rms. Checking the crystalline quality of the layer was achieved by cathodoluminescence, described in detail in Ref. 17, and found comparable to that of the sample analyzed in Ref. 18. An averaged boron concentration of $(1.4-2.8) \times 10^{16} \mathrm{~cm}^{-3}$, due to the residual boron inside the reactor, was derived.

Schottky contacts with a diameter of $150 \mu \mathrm{m}$ have been achieved by gold deposition through holes in a metallic mask on the epilayer surface treated by ozone produced by vuv light as described in Ref. 16. Four Ti/Au Ohmic contacts were deposited and annealed $1 \mathrm{~h}$ at $750{ }^{\circ} \mathrm{C}$ in the corners of the sample after an acid cleaning of the surface, before vuv ozone treatment and Schottky metallization. Metallic tips were used to connect the measurement set up to the metallic contacts deposited on diamond. The current-voltage $\mathrm{I}(\mathrm{V})$ characteristics between two Ohmic contacts have been performed after each $\mathrm{I}(\mathrm{V})$ measurements done on the Schottky diodes in order to check that the contacts remain Ohmic and not rectifying. I(V) characteristics of the Schottky diodes have been studied on the one hand at low voltages in the as-grown epilayer, after a first anneal at $750{ }^{\circ} \mathrm{C} 10 \mathrm{~min}$. and a second anneal at $825{ }^{\circ} \mathrm{C} 1 \mathrm{~h}$, both under vacuum, and on the other hand under several kilovolt reverse voltages, without reaching avalanche breakdown. ${ }^{17}$ In between each annealing process, Schottky metal deposits are removed by 


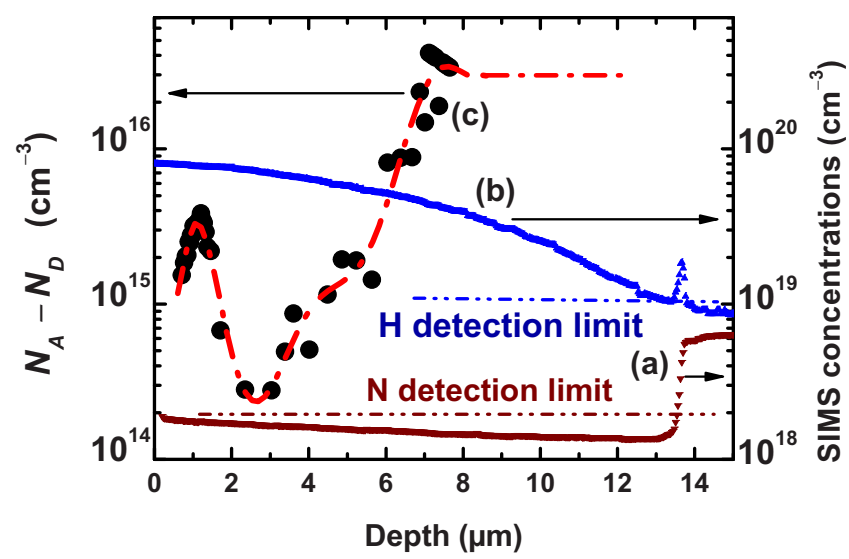

FIG. 1. (Color online) SIMS profiles of (a) nitrogen (not calibrated), only to show the step due to the Ib substrate; (b) hydrogen, in the sample after the second anneal. Data and curve (c) give the net acceptor concentration derived from the $\mathrm{C}-\mathrm{V}$ characteristic, all as a function of depth inside the epilayer.

chemical treatment, and then deposited again after a new vuv ozone treatment. After each anneal, the current level increases in the whole voltage range, both in forward and reverse bias. ${ }^{17}$ As the hydrogen concentration in the as-grown epilayer initially amounted up to $8 \times 10^{19} \mathrm{~cm}^{-3}$, above the SIMS detection limit of $\sim 10^{19} \mathrm{~cm}^{-3}$ as shown in Fig. 1, the subsequent anneals have depassivated the boron acceptors which were previously passivated by hydrogen, like found in Refs. 7 and 19. It is statistically probable that BH complexes leading to deep levels ${ }^{20}$ can form readily when the concentration of hydrogen is more than three orders of magnitude larger than that of boron, even if the growth temperature is above that known for $\mathrm{BH}$ pairs dissociation when the concentration of the two species are of same magnitude. ${ }^{21}$ Then, the net ionized acceptor concentration increased as well as the electric field in the space charge zone, inducing an increase of the current levels. Moreover, the potential barrier height grew by about $1 \mathrm{~V}$ after the second anneal. This fact was not expected if the Fermi level position would have stayed the same because of an unchanged metal-diamond interface. But it is known that hydrogen trapped into the subsurface atomic layers of diamond induces an electrical dipole which decreases the effective barrier height by about $1 \mathrm{~V},{ }^{22}$ as found experimentally here again. Consequently, one must conclude that the second anneal has decreased the subsurface hydrogen concentration.

Only after the second anneal, it became possible to probe the depletion zone thickness and net ionized acceptor charge by $\mathrm{C}-\mathrm{V}$ measurements. They were performed with an Agilent E4980A bridge at a frequency of $1.2 \mathrm{kHz}$ and a temperature of $400 \mathrm{~K}$, well below the cut-off frequency of the diode, with the help of a special circuit and external source allowing dc biasing up to $800 \mathrm{~V}$. The width $w$ of the space charge zone (and therefore the probed depth) was deduced from $\varepsilon_{r} \varepsilon_{0} / C$ where $\varepsilon_{r}$ and $\varepsilon_{0}$ are, respectively, the relative and vacuum permittivity, and $C$ the capacitance per unit area. The net acceptor concentration $N_{A}-N_{D}$ was then calculated from $C^{3} /\left(e \varepsilon_{r} \varepsilon_{0} d C / d V\right)$ where $e$ is the elementary charge and $V$ the applied reverse voltage, for $w$ between 0.6 and $7.7 \mu \mathrm{m}$, as displayed in Fig. 1. The net acceptor concentration appears as not constant, fluctuating between $2.5 \times 10^{14}$ and 4 $\times 10^{15} \mathrm{~cm}^{-3}$, because of a residual passivation of boron by hydrogen in the first $6 \mu \mathrm{m}$ of the epilayer. Then, it reaches

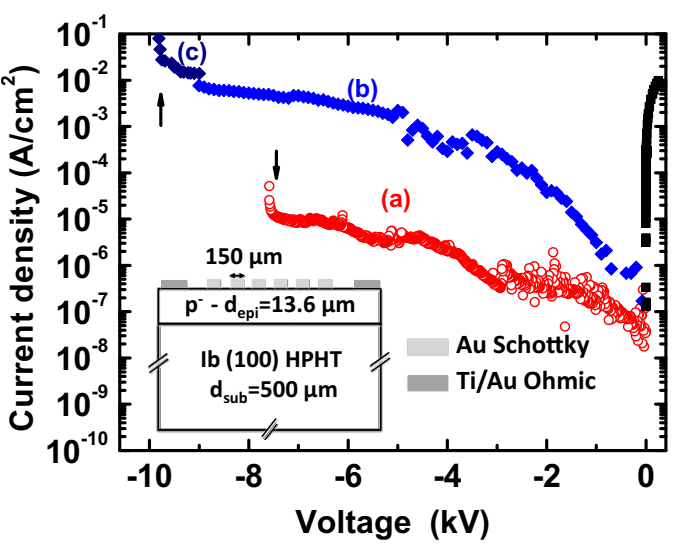

FIG. 2. (Color online) Current density as a function of voltage under vacuum in two Schottky diodes (a)-(c). (a) and (b) characteristics have been recorded with a ramp voltage of $5 \mathrm{~V} / \mathrm{s}$ while (c) has been recorded manually. Arrows delineate avalanche breakdown voltages. A schematic cross section of the structure of the sample is drawn.

$3 \times 10^{16} \mathrm{~cm}^{-3}$ between depths of 6.7 and $7.7 \mu \mathrm{m}$. If an average value is calculated from the surface down to the epilayer thickness which is $13.6 \mu \mathrm{m}$, as deduced from SIMS measurements performed for $\mathrm{H}$ and $\mathrm{N}$ atomic masses (Fig. $1)$, it compares very well with the boron concentration deduced from the cathodoluminescence experiment. Then, the net acceptor concentration will be assumed to keep the same level of $3 \times 10^{16} \mathrm{~cm}^{-3}$ from a depth of $6.7 \mu \mathrm{m}$ down to the interface with the Ib substrate.

The current-voltage characteristics of several diodes were investigated with the help of four different experimental setups which provided increasing maximum voltages along five runs which took place in a period of 15 months after the last sample processing. In the two first attempts, the voltage was limited to $1 \mathrm{kV}$ and it is important to notice that about half the diodes displayed the same characteristic as in Ref. 16 with a negligible dispersion, even nine months after the last vuv ozone treatment and Schottky metallization. The third test was performed in air, and displayed a breakdown at $5.5 \mathrm{kV},{ }^{17}$ resulting from disruption between the metallic tips used for contacting the Schottky and Ohmic dots on the sample. The fourth test was performed in vacuum on the same diode, ten months after fabrication, and displayed an avalanche breakdown at $7.5 \mathrm{kV}$ [Fig. 2(a)] with current densities comparable to that given in Ref. 7. A fifth measurement run was performed in the same setup, 13 months after fabrication, on an other diode which withdrew almost $10 \mathrm{kV}$ before avalanche breakdown [Figs. 2(b) and 2(c)]. In this last case, higher current densities presumably resulted from pollution of the diamond surface by metallic dust outside the Schottky contact, which took place under vacuum and high electric fields, because of redeposition of the silver paste used to stick the sample on the ceramic holder, as it was visible from optical inspection. Meanwhile, these surface modifications did not affect the breakdown electric field.

Integrating $e\left(N_{A}-N_{D}\right) /\left(\varepsilon_{r} \varepsilon_{0}\right)$ along the depth $w$ gives the maximum field reached at the metal-diamond interface in a one-dimensional model, and yields 7.3 and $9.3 \mathrm{MV} / \mathrm{cm}$, respectively, at reverse voltages of 7.5 and $9.8 \mathrm{kV}$. But the second value is obtained together with a depletion zone thickness which exceeds that of the epilayer, casting some doubt on it. This is the reason for using two-dimensional simulations, achieved with the software "SENTAURUS 
$\mathrm{TCAD}^{\text {,23 }}$ and the parameters deduced from the diode geometry and doping profile, leading, respectively, to 7.2 and 7.7 $\mathrm{MV} / \mathrm{cm}$ at the center of the diode, and more than $20 \mathrm{MV} / \mathrm{cm}$ at the edge of the Schottky dot. But this last value is less reliable than values at the diode center because field enhancement at the diode edge depends on the precise geometry, conductivity, and dielectric permittivity of each material, ${ }^{24,25}$ not accurately known. It must be noticed that the voltage drop induced by the serial resistance of the Schottky diode leads to an overestimation of the electric field equal or lower than $2.5 \%$. Recently, Rashid et $_{\text {al. }}{ }^{26}$ estimated values of diamond impact ionization coefficients via extrapolation from silicon and silicon carbide based on the band gap of diamond. Using their parameters in our simulation, the breakdown voltage of the structure reported here leads to an underestimated value of $1 \mathrm{kV}$ showing that these parameters are not accurate for such breakdown voltage estimations.

However, the low net doping concentration due to residual passivation by hydrogen close to the surface remains a decisive factor which limits the electric field. Moreover, the oxygen terminated coating resulting from vuv ozone treatment is believed to be useful both for passivating electrically the bare diamond surface outside the Schottky contacts and preventing carbide formation at the metal diamond interface, which would otherwise generate detrimental defects. This treatment is able to reveal the true dielectric strength of bulk diamond. The record values obtained here were not possible with other surface processing.

According to the results and analysis presented in this study, it can be concluded that diamond homoepitaxial layers are able to withstand electric fields in the range predicted in Ref. 1 before avalanche breakdown, far higher than those known in all other semiconductors, provided an oxidation process of the surface resulting in superior electrical and chemical passivations efficiencies has been applied. These findings open the route for implementing high voltage diodes and other unipolar electronic devices.

${ }^{1}$ M. I. Landstrass, M. A. Plano, M. A. Moreno, S. McWilliams, L. S. Pan, D. R. Kania, and S. Han, Diamond Relat. Mater. 2, 1033 (1993).

${ }^{2}$ R. Berman, P. R. W. Hudson, and M. Martinez, J. Phys. C 8, L430 (1975).

${ }^{3}$ L. Reggiani, S. Bosi, C. Canali, F. Nava, and S. F. Kozlov, Phys. Rev. B 23, 3050 (1981).

${ }^{4}$ P.-N. Volpe, J. Pernot, P. Muret, and F. Omnès, Appl. Phys. Lett. 94,
092102 (2009); J. Pernot, P. N. Volpe, F. Omnès, P. Muret, V. Mortet, K. Haenen, and T. Teraji, Phys. Rev. B 81, 20520 (2010).

5 J. Pernot and S. Koizumi, Appl. Phys. Lett. 93, 052105 (2008)

${ }^{6}$ J. Isberg, J. Hammersberg, E. Johansson, T. Wikström, D. J. Twitchen, A.

J. Whitehead, S. E. Coe, and G. A. Scarsbrook, Science 297, 1670 (2002).

${ }^{7}$ J. E. Butler, M. W. Geis, K. E. Krohn, J. Lawless, Jr., S. Deneault, T. M. Lyszczarz, D. Flechtner, and R. Wright, Semicond. Sci. Technol. 18, S67 (2003).

${ }^{8}$ W. Huang, T. P. Chow, J. Yang, and J. E. Butler, Int. J. High Speed Electron. Syst. 14, 872 (2004).

${ }^{9}$ D. W. Twitchen, A. J. Whitehead, S. E. Coe, J. Isberg, J. Hammersberg, T. Wikstrom, and E. Johansson, IEEE Trans. Electron Devices 51, 826 (2004).

${ }^{10}$ A. Vescan, I. Daumiller, P. Gluche, W. Ebert, and E. Kohn, Diamond Relat. Mater. 7, 581 (1998).

${ }^{11}$ T. Teraji, S. Koizumi, Y. Koide, and T. Ito, Appl. Surf. Sci. 254, 6273 (2008).

${ }^{12}$ H. Umezawa, K. Ikeda, N. Tatsumi, K. Ramanujam, and S. Shikata, Diamond Relat. Mater. 18, 1196 (2009).

${ }^{13}$ H. Umezawa, N. Tokuda, M. Ogura, S.-G. Ri, and S. Shikata, Diamond Relat. Mater. 15, 1949 (2006).

${ }^{14}$ M. Craciun, C. Saby, P. Muret, and A. Deneuville, Diamond Relat. Mater. 13, 292 (2004).

${ }^{15}$ R. Kumaresan, H. Umezawa, N. Tatsumi, K. Ikeda, and S. Shikata, Diamond Relat. Mater. 18, 299 (2009).

${ }^{16}$ T. Teraji, Y. Garino, Y. Koide, and T. Ito, J. Appl. Phys. 105, 126109 (2009).

${ }^{17}$ P.-N. Volpe, P. Muret, J. Pernot, F. Omnès, T. Teraji, F. Jomard, D. Planson, P. Brosselard, N. Dheilly, B. Vergne, and S. Scharnholtz, Phys. Status Solidi A 207, 2088 (2010).

${ }^{18}$ P.-N. Volpe, P. Muret, F. Omnès, J. Achard, F. Silva, O. Brinza, and A. Gicquel, Diamond Relat. Mater. 18, 1205 (2009).

${ }^{19}$ R. Zeisel, C. E. Nebel, and M. Stutzmann, Appl. Phys. Lett. 74, 1875 (1999)

${ }^{20}$ P. Muret, J. Pernot, A. Kumar, L. Magaud, C. Mer-Calfati, and P. Bergonzo, Phys. Rev. B 81, 235205 (2010).

${ }^{21}$ J. Chevallier, B. Theys, A. Lusson, C. Grattepain, A. Deneuville, and E. Gheeraert, Phys. Rev. B 58, 7966 (1998).

${ }^{22}$ W. Mönch, Europhys. Lett. 27, 479 (1994).

${ }^{23}$ See www.synopsys.com for Sentaurus device user guide version D-2010.03, March 2010.

${ }^{24}$ K. Ikeda, H. Umezawa, N. Tatsumi, K. Ramanujam, and S. Shikata, Diamond Relat. Mater. 18, 292 (2009).

${ }^{25}$ It is well known that finite element software is not able to calculate the electric field near discontinuity like the edge of the Schottky metal of this work. Generally the result is mesh size dependent. Also, in this work and for the edge value only, we consider the electric field at $1 \mu \mathrm{m}$ from the edge. In this case, the field value is mesh size independent.

${ }^{26}$ S. J. Rashid, A. Tajani, L. Coulbeck, M. Brezeanu, A. Garraway, T. Butler, N. L. Rupesinghe, D. J. Twitchen, G. A. J. Amaratunga, F. Udrea, P. Taylor, M. Dixon, and J. Isberg, Diamond Relat. Mater. 15, 317 (2006). 